\title{
New Therapeutic Approach of Retinoids for Lupus Nephritis
}

Yuji Nozaki, Masanori Funauchi, Itaru Matsumura and Koji kinoshita*

Department of Hematology and Rheumatology, Kinki University, Faculty of Medicine, Osaka-Sayama, Japan

Keywords: Retinoids; Lupus nephritis

\section{Introduction}

Lupus nephritis is a major cause of morbidity and mortality in patients with Systemic Lupus Erythematosus (SLE) [1]. Nephritis may then progress to a chronic phase, characterized by excessive deposition of collagen and other extracellular matrix macromolecules [2]. Lupus nephritis is also believed to result mostly from renal deposition of autoantibodies and immune complexes [3], which in turn triggers an acute inflammatory response characterized by activation of leukocytes and renal parenchymal cells. This activation is accompanied by the production of cytokines and growth factors. The glomerulus is one of the sites most seriously affected, with tissue damage progressing to end-stage renal disease in as much as $30 \%$ of patients. Although various functional disturbances within tissues have been implicated in the pathogenesis of SLE, details of the initiating events and accompanying detrimental processes on both systemic and end-organ levels remain largely unknown. Current therapies, such as corticosteroids, cyclophosphamide and azathioprine, are largely cytotoxic in nature and are associated with undesirable side effects. More targeted therapies aimed at depleting or modulating the activity of pathogenic lymphocytes may represent a more effective and safer alternative. For example, approaches, such as treatment with a monoclonal antibody against the B cell growth factor, B-lymphocyte stimulator [4], or depletion of B lymphocytes with Rituximab [5], are currently being tested. However, these agents have severe potential side effects, including increased susceptibility to infections and the development of malignant tumors [6]. Therefore, the development of new drugs with few side effects is needed in the patients.

Retinoids are a group of natural and synthetic derivatives of vitamin A that exert antineoplastic and immunomodulatory actions and they have been used for the treatment of acute promyelocytic leukemia [7] and such inflammatory disorders as psoriasis [8], acne [9] and rheumatoid arthritis [10]. Recently, we reported retinoids showed excellent therapeutic efficacy in human lupus nephritis [11]. Retinoids also improve renal pathological findings and proteinuria in various animal models of kidney disease. Retinoid treatment can prevent proteinuria by protecting renal injury and diminishing leukocytes infiltrating in lupus model mice [12]. Furthermore, retinoids prevent renal interstitial fibrosis in the unilateral ureteral obstruction model [13]. These studies also suggest that retinoids could be a promising new medication for treatment of lupus nephritis. The goal of each of treatments has been to achieve clinical efficacy by inducing a remission of the nephritis while at the same time minimizing severe side effects of treatment. This review article focuses on the potential advantages of retinoids treatment in lupus nephritis.

\section{Pathogenesis}

SLE is an autoimmune condition characterized by the development of autoantibodies against various cellular components, most notably dsDNA, a hallmark of the disease. The pathogenesis of the disease is not fully understood but appears to involve defects in the activity of regulatory $\mathrm{T}$ cell (Treg) [14] and abnormal activation of auto reactive $\mathrm{B}$ and $\mathrm{T}$ lymphocytes [15]. The histological presentation and patterns of glomerular injury in lupus nephritis are heterogeneous, with varying involvement of mesangial and vascular elements. An invariant finding, however, is the accumulation of immune complexes within glomerular membranes, which is often accompanied by an apparent expansion of vascular and /or mesangial extracellular matrices as the disease progresses. Autoantibodies against dsDNA are considered to be an important factor in the evolution of lupus nephritis. Several nephritogenic anti-dsDNA antibodies appear to bind DNA in the form of nucleosomes and extracellular chromatin has been found to colocalize with such antibodies in situ [16]. Recent data demonstrated considerable affinity of nucleosomes for collagen IV [16]. Increased production or reduced degradation of collagen IV might theoretically contribute to accumulation of extracellular chromatin, thus maintaining or aggravating autoantibody deposition. The causes underlying the observed glomerular basement membrane thickening are unknown, but it has been speculated that increased synthesis or decreased turnover of extracellular matrix constituents such as collagen IV might be contributing factors [16].

Recently, there have been several reports that abnormalities of both the Th1 and Th2 cells are associated with the pathogenesis of autoimmune disorders $[17,18]$. Among the Th1 cytokines IFN- $\gamma$, the production of which is promoted by IL-12, plays a key regulatory role in the development of autoimmune kidney diseases and deletion of IFN- $\gamma$ receptor or IFN- $\gamma$ genes or administration of anti-IFN- $\gamma$ monoclonal antibody improved the survival rate of lupus-prone mice [19-22]. IL-12 has been reported to promote $\mathrm{T}$ cell proliferation [23] and differentiation of CD4+ T cells into Th1 cells [24] and its production by tubular epithelial cells and macrophages is up-regulated along with the development of lupus nephritis in MRL-Fas ${ }^{\mathrm{lpr}}$ mice [25,26]. Among the Th2 cytokines, IL- 4 enhances the differentiation of both B cells and $\mathrm{T}$ cells (especially Th2 cells) and increased production of IL-4 is also associated with the pathogenesis of SLE [27] and lupus nephritis [28]. Development of kidney disease is one of the most serious consequences of SLE.

\section{Current Agents for the Treatment of Lupus Nephritis}

\section{Cyclophosphamide}

Cyclophophamide is given as intravenous pulses to achieve remission in severe SLE and lupus nephritis. The modified National Institute of Health protocol of 6 monthly intravenous pulses of cyclophosphamide at $0.5-1 \mathrm{~g} / \mathrm{m}^{2}$ with dose reduction in renal failure,

*Corresponding author: Koji kinoshita, Department of Hematology and Rheumatology, Kinki University Faculty of Medicine, Japan, E-mail: kkino@med.kindai.ac.jp

Received November 15, 2011; Accepted December 16, 2011; Published January 03, 2012

Citation: Nozaki Y, Funauchi M, Matsumura I, kinoshita K (2012) New Therapeutic Approach of Retinoids for Lupus Nephritis. J Data Mining in Genom Proteomics 3:112. doi:10.4172/2153-0602.1000112

Copyright: ( 2012 Nozaki Y, et al. This is an open-access article distributed under the terms of the Creative Commons Attribution License, which permits unrestricted use, distribution, and reproduction in any medium, provided the original author and source are credited. 
with 3-monthly pulses thereafter, is normally reduced because of the short- and long-term side-effects, such as haemorrhagic cystitis (with mesna given with additional fluids for prophylaxis), neutropenia and infectious complications, nausea, alopecia, amenorrhoea and infertility. Despite protective measures, there are significantly more side-effects with cyclophosphamide, including severe infections compared with oral azathioprine or MMF [29-32]. Patients require blood tests at around 7-10 days after infusions to monitor the safety and efficacy of treatment with total white cell, neutrophil and lymphocyte counts with subsequent dosing based on hematological results. Amenorrhea, infertility and malignancy risks are increased with cyclophosphamide [33].

\section{Mycophenolate mofetil}

MMF effectively and selectively suppresses $\mathrm{T}$ and B lymphocyte proliferation, antibody production and expression of proinflammatory adhesion molecules on lymphocytes [34]. It was initially administered to prevent acute rejection of renal allografts [35] but is currently also applied in the treatment of primary glomerulonephritis and lupus nephritis [36]. MMF has been used for induction and maintenance treatment, especially in patients with severe lupus nephritis, those with lupus nephritis refractory to cyclophosphamide and subjects who cannot tolerate cyclophosphamide.

\section{Tacrolimus}

Tacrolimus is a macrolide calcineurin inhibitor that potently suppresses human T-cell proliferation by inhibiting the intranuclear translocation of cytoplasmic nuclear factors in activated $\mathrm{T}$ cells by binding to tacrolimus-binding proteins and inhibiting calcineurin. Compared with cyclosporine, it seems more prospective in prevention of transplant rejection and is associated with less hypertensive and adverse cosmetic effects. Early anecdotal experiences suggest that tacrolimus could be a treatment option for patients with lupus and topical tacrolimus has been used in the treatment of lupus dermopathy [37]. However, the side effects of tacrolimus such as diabetogenesis and nephrotoxicity remain valid concerns. Little evidence of randomized controlled trials has been published on the efficacy and safety when administered with corticosteroids treatment of lupus nephritis.

\section{New agents for the Treatment of Lupus Nephritis}

\section{Rituximab}

Rituximab is a chimeric antibody directed against CD20, a phosphoprotein expressed on almost all B cells but not on plasma cells. Therefore, through the elimination of B cells rituximab may prevent the generation and expansion of antibody-secreting autoreactive cells [38]. Using rituximab to deplete B cells may have the advantage of being generally well tolerated and to spare $\mathrm{T}$ cells and plasma cells, which are CD20-negative [39]. However, double-blind controlled trials are advocated to confirm its role in lupus nephritis and to find whether rituximab alone may be effective or should be associated with other drugs and, in the latter case, what the combination that offers the best therapeutic index is. Until these data are available, the use of rituximab should be confined to cases resistant to standard induction therapy or to patients with contraindications to corticosteroids and immunosuppressive agents.

\section{Belimumab}

Belimumab binds soluble B-lymphocyte stimulator B-cell activating factor, which is a member of the tumor necrosis factor family and a

cytokine that is essential for B-cell growth, differentiation and survival. Belimumab inhibits the factor's biological activity [40]. A study of belimumab in SLE patients (BLISS-52 and BLISS-76) showed that it improved the clinical symptoms, serological profiles and markers of renal function, as well as prevented SLE flares [41]. In addition, belimumab was found to be well tolerated.

\section{Abatacept}

Abatacept is a selective T-cell costimulation modulator that has been approved for use in adult rheumatoid arthritis and juvenile idiopathic arthritis. T-cell activation, a crucial step in the pathogenesis of glomerulonephritis, requires both binding of the T-cell receptor to the antigen-major histocompatibility complex on the antigenpresenting cell and a costimulatory signal provided by binding of the $\mathrm{CD} 28$ protein (on the $\mathrm{T}$ cell) to the $\mathrm{B} 7$ protein (on the antigen presenting cell). Abatacept binds to the $\mathrm{B} 7$ protein, thereby preventing this costimulatory signal and, in turn, preventing activation of $\mathrm{T}$ cells [42]. Two current clinical trials are exploring the use of abatacept in lupus nephritis as add-on induction phase therapy to the Euro-Lupus cyclophosphamide regimen or MMF [43].

\section{Retinoids}

Vitamin A and its metabolites: The term retinoids is applied to a family of compounds that bind to and activate retinoic acid receptors (RARs and RXRs), resulting in a range of possible biological responses. Some natural retinoids, such as ATRA (Tretinoin), 9-cis RA (Alitretinoin) and 13-cis RA (Isotretinoin), are currently already used in the clinic. As the clinical use of natural retinoids is limited by their pharmacological profile, including instability, poor bioavailability and the possible side effect due to the nonspecific receptor binding of those natural retinoids, a number synthetic retinoids have been generated. These include mono-aromatic synthetic retinoids (second generation), such as Tamibarotene (Am80), Tazarotene and Targretene (LGD1069) (Table 1). The aromatic rings found in the second and third generation retinoids confer a higher stability and resistance to heat/oxidation, increased half-lives, a higher potency and improved spectrum of action with receptor specificities.

The first group are natural provitamin A, vitamin A and other RA precursors, which cannot bind retinoid nuclear receptors, but are characterized by their potential to be converted into retinoids; the second group includes the natural retinoids, including ATRA and 13-cis-RA, which bind and activate RARs and 9-cis-RA, which binds and activates both RARs and RXRs.The third group is composed of synthetic retinoids, which bind one or more RAR or/and RXR isotypes and exert agonistic or antagonistic actions. Some of the third group activate neither RARs nor RXRs, but have selective anti-activator protein-1 activity [44]. Although vitamin A does not bind any of the nuclear receptors, the majority of its functions are retinoid nuclear receptor-dependent; therefore, conversion of vitamin A into RAs that

\begin{tabular}{|l|c|c|}
\hline Name & Receptors & Clinical use \\
\hline ATRA & pan-RAR & APL, Acne \\
\hline 9-cis RA & pan-RAR, pan-RXR & Kaposi sarcoma \\
\hline 13-cis RA & - & Acne \\
\hline Etretinate & - & Psoriasis \\
\hline Acitretin & pan-RAR & Psoriasis \\
\hline Tamibarotene & RAR $/ \beta » Y$ & APL \\
\hline Tazarotene & RAR $\beta / y » \alpha$ & Acne \\
\hline Targretin & pan-RXR & Cutaneus T lymphoma \\
\hline \multicolumn{2}{|c|}{} \\
\hline
\end{tabular}


can bind retinoid nuclear receptors is largely a process of vitamin A activation [44].

Effect of RA on cytokines and modulating $\mathrm{T}$ regulatory cell differentiation: Recent studies have shown that RA, in concert with TGF- $\beta$, has ability to induce Foxp3 (forkhead box 3 ) in CD4+ T cells $[45,46]$. Foxp $3+$ CD $4+$ Treg cells play a pivotal role in the maintenance of dominant self tolerance and lack of functional Treg cells is associated with various autoimmune diseases. A recent study has shown that the decreased frequency of Treg cells in the peripheral blood was associated with disease activity in SLE patients [47]. Specific subsets of intestinal antigen presenting cells have the capacity to produce RA and induce to Foxp3+ Treg in vitro, in the presence of TGF- $\beta[45,46]$. Foxp3+CD4+ cells are reciprocally linked with the development of Th17 effector cells 6, 7 and recent studies suggest that these Foxp3+ Tregs cells can regulate both Th1 and Th17 mediated effector responses. In experimental murine glomerulonephritis, both Th1 and Th17 effector subsets and their respective signature cytokines, IFN- $\gamma$ and IL-17A, can mediate severe glomerular disease [48-50]. In addition to its role in inducing $\mathrm{T}$ regulatory cells, accumulating evidence suggest $\mathrm{RA}$, at high concentrations, suppresses Th1 and Th17 differentiation by suppressing the lineage specific transcription factors and also by suppressing the expression of effector cytokines IFN- $\gamma$ and IL-17 [51].

\section{Potential Advantages of Retinoids in Lupus Nephritis}

Recently, RA, a family of vitamin A metabolites or analogs, have been shown to have excellent preventive and therapeutic effects in various experimental kidney diseases, as shown in Table 2 [11,13, 28,52-60]. RA might prove useful in the treatment of various renal conditions, some of which, such as hypertensive nephropathy, focal-segmental glomerulosclerosis, pyelonephritis and renal interstitial fibrosis, are contraindicated in the use of glucocorticoids. One of the most important adverse effects of glucocorticoids and cytotoxic agents is the risk of infection. In contrast, as shown in Table 2, RA have been used in both infective and non infective renal inflammation and have rarely been reported to induce severe acquired infection in patients. This might be due to the fact that the effect of RA on immunity is "immune modulation" rather than a nonspecific "immune suppression". Emerging evidence indicates that, although RA is potent antiinflammatory agents, they may also have proinflammatory potential by inducing some proinflammatory molecules. For example, RA can induce inducible nitric oxide expression in vivo [61] and enhance IL-8 [62] and intercellular adhesion molecule-1 [63] expression in vitro. Further, since ATRA has been shown to potentiate tubulointerstitial nephritis both in patients and in animal models $[11,27]$. We previously reported that ATRA treatment in SLE-prone New Zealand Black/ White F1 mice significantly alleviates autoimmune renal disorder and prolongs survival.6 In that report, we showed that ATRA inhibits

\begin{tabular}{|l|l|c|}
\hline Model & Response to RA & Reference \\
\hline Acute Thy1.1 nephritis & + & 52 \\
\hline Chronic Thy1.1 nephritis & + & 53 \\
\hline Puromycin aminonucleoside nephrosis & + & 54 \\
\hline Lupus nephritis & + & 11,28 \\
\hline Acute kidney allograft rejection & + & 55 \\
\hline Aging related nephropathy & + & 56 \\
\hline Unilateral ureteral obstruction & + & 13 \\
\hline Pyelonephritis & + & 57 \\
\hline Anti-GBM nephritis (chronic phase) & + & 58 \\
\hline Anti-GBM nephritis (acute phase) & \pm & 59 \\
\hline Radiation nephritis & - & 60 \\
\hline
\end{tabular}

Note: + , renal damage reduced; \pm , proteinuria unchanged; -, renal damage enhanced

Table 2:Effects of retinoic acid on animal models of renal disease
IFN- $\gamma$ expression, leading to decreased immunoglobulin G2a antiDNA antibody production and immunoglobulin G2a deposition in glomeruli and results in the prevention of fatal autoimmune kidney disease in New Zealand Black/White F1 mice. Furthermore, ATRA has the potential to act as a steroid-sparing drug against lupus nephritis [64]. The mechanisms by which retinoids improve lupus nephritis are difficult to elucidate because retinoids have potent antiproliferative and antiinflammatory effects. For example, treatment with retinoids can ameliorate renal injury in anti-Thyl.1-nephritis rat models by reducing proliferating cell nuclear antigen-positive cells, platelet derived growth factor B-chain and transforming growth factor [6567]. In addition, retinoid treatment can prevent proteinuria by protecting podocytes from injury and diminishing infiltrating cells in puromycin aminonucleoside nephrosis rat models [54]. Retinoids also attenuate inducible nitric oxide synthase, which causes oxidative injury in glomerulonephritis [61]. Furthermore, retinoids prevent renal interstitial fibrosis in the unilateral ureteral obstruction model [13] We also report a dramatic therapeutic response to ATRA in 2 patients with lupus nephritis [11]. ATRA treatment rapidly improved clinical symptoms and laboratory findings, including urinary protein and antids-DNA antibody levels of these patients. In both patients, ATRA was administered for 6 months and stopped after complete remission was achieved. Thus, RA might be indicated in cases of lupus nephritis that are refractory to conventional immunosuppressive therapy.

\section{Conclusion and Perspectives}

RA target mesangial cells, podocytes, tubular epithelial cells, interstitial fibroblasts, as well as $\mathrm{T}$ lymphocytes and macrophages and have antiinflammatory, anticoagulatory, antifibrotic effects and proliferation- and immunity-modulating actions. All these features make RA a promising new generation of renal medication for use in lupus nephritis of renal diseases. The pharmacologic effects of RA reported in animal studies suggest that it may be worthwhile to examine whether RA can be useful in dealing with the following conditions of lupus nephritis (1) steroid-resistant glomerulonephritis, such as focal segmental glomerulosclerosis, membranous nephropathy and membranous proliferative glomerulonephritis; (2) glomerulonephritis responsive to but developing secondary resistance to steroids, such as refractory minimal change nephrosis, mesangioproliferative glomerulonephritis; (3) glomerulonephritis with mild to moderate chronic renal failure and renal fibrosis; (4) glomerulonephritis complicated by diabetes or other side effects of steroids; (5) crescentic glomerulonephritis; (6) renal transplantation.

Here we describe the agents of the treatment in lupus nephritis. The goal of treatments has been to achieve clinical efficacy by inducing a remission of the nephritis while at the same time minimizing severe side effects. Retionoids have many immunomodulatory actions while it has no severe side effects. Retinoids could be a promising new medication for treatment of lupus nephritis.

\section{References}

1. Walsh SJ, Algert C, Gregorio DI, Reisine ST, Rothfield NF (1995) Divergent racial trends in mortality from systemic lupus erythematosus. J Rheumatol 22 1663-1668.

2. Grande JP (1998) Mechanisms of progression of renal damage in lupus nephritis: Pathogenesis of renal scarring. Lupus 7: 604-610.

3. Santoro TJ, Portanova JP, Kotzin BL (1988) The contribution of L3T4+T cells to lymphoproliferation and autoantibody production in MRL-Ipr/lpr mice. J Exp Med 167: 1713-1718.

4. Navarra SV, Guzmán RM, Gallacher AE, Hall S, Levy RA, et al. (2011) Efficacy 
and safety of belimumab in patients with active systemic lupus erythematosus: a randomised, placebo-controlled, phase 3 trial. Lancet 377: 721-731.

5. Turner-Stokes T, Lu TY, Ehrenstein MR, Giles I, Rahman A, et al. (2011) The efficacy of repeated treatment with B-cell depletion therapy in systemic lupus erythematosus: an evaluation. Rheumatology (Oxford) 50: 1401-1408.

6. Baker GL, Kahl LE, Zee BC, Stolzer BL, Agarwal AK, et al. (1987) Malignancy following treatment of rheumatoid arthritis with cyclophosphamide. Long-term casecontrol follow-up study. Am J Med 83: 1-9.

7. Huang ME, Ye YC, Chen SR, Chai JR, Lu JX, et al. (1988) Use of all-trans retinoic acid in the treatment of acute promyelocytic leukemia. Blood 72: 567 572

8. Ward A, Brogden RN, Heel RC, Speight TM, Avery GS (1983) Etretinate: a review of its pharmacological properties and therapeutic efficacy in psoriasis and other skin disorders. Drugs 26: 9-43.

9. Peck GL, Olsen TG, Butkus D, Pandya M, Arnaud-Battandier J, et al. (1982) Isotretinoin versus placebo in the treatment of cystic acne: a randomized double-blind study. J Am Acad Dermatol 6: 735-745.

10. Brinckerhoff CE (1990) Retinoids and rheumatoid arthritis: modulation of extracellular matrix by controlling expression of collagenase. Methods Enzymo 190: $175-188$

11. Kinoshita K, Kishimoto K, Shimazu H, Nozaki Y, Sugiyama M, et al.(2009) Successful Treatment With Retinoids in Patients With Lupus Nephritis. Am J Kidney Dis 55: 344-347.

12. Kinoshita K, Yoo BS, Nozaki Y, Sugiyama M, Ikoma S, et al.(2003) Retinoic Acid Reduces Autoimmune Renal Injury and Incresses Survival in NZB/W F1 Mice. J Immunol 170: 5793-5798.

13. Kishimoto K, Kinoshita K, Hino S, Yano T, Nagare Y, et al.(2011) Therapeutic Effect of Retinoic Acid on Unilateral Ureteral Obstruction Model. Nephron Exp Nephrol 13: 69-78.

14. Miyara M, Amoura Z, Parizot C, Badoual C, Dorgham K, et al.(2005) Globa natural regulatory $\mathrm{T}$ cell depletion in active systemic lupus erythematosus. J Immunol 175: 8392-8400.

15. O.T. Chan, M.J. Shlomchik (1998) A new role for B cells in systemic autoimmunity: B cells promote spontaneous $\mathrm{T}$ cell activation in MRL-lpr/lpr mice. J Immunol 160: 51-59.

16. Rosenberg AM, Prokopchuk PA (1986) The binding of dsDNA and ssDNA to human types I, II and IV collagens. J Rheumatol 13: 512-516.

17. Romagnani $S$, Parronchi $P$, D'Elios MM, Romagnani $P$, Annunziato $F$, et al (1997) An update on human Th1 and Th2 cells. Int Arch Allergy Immunol 113: 153-156.

18. Theofilopoulos AN, Dixon FJ (1985) Murine models of systemic lupus erythematosus. Adv Immunol 37: 269-390.

19. Gately MK, Desai BB, Wolitzky AG, Quinn PM, Dwyer CM, et al.(1991) Regulation of human lymphocyte proliferation by a heterodimeric cytokine, IL12 (cytotoxic lymphocyte maturation factor). J Immunol 147: 874-882.

20. Jacob CO, van der Meide PH, McDevitt HO (1987) In vitro treatment of (NZB/ NZW) F1 lupus-like nephritis with monoclonal antibody to $y$ interferon. $J$ Exp Med 166: 798-803.

21. Balomenos D, Rumold R, Theofilopoulos AN (1998) Interferon-gamma is required for lupus-like disease and lymphoaccumulation in MRL-Ipr mice. J Clin Invest 101: 364-371.

22. Haas C, Ryffel B, Le HM (1998) IFN-g receptor deletion prevents autoantibody production and glomerulonephritis in lupus-prone (NZB/NZW) F1 mice. J Immunol 160: 3713-3718.

23. Seder RA, Gazzinelli R, Paul WE (1993) Interleukin 12 acts directly on CD4+ $T$ cells to enhance priming for interferon gamma production and diminishes interleukin 4 inhibition of such priming. Proc Natl Acad Sc USA 90: 1018810192

24. Chang TL, Shea CM, Urioste S, Thompson RC, Boom WH, et al. (1990) Heterogeneity of helper/ inducer T lymphocytes III. Responses of IL-2- and IL4-producing (Th1 and Th2) clones to antigens presented by different accessory cells. J Immunol 145: 2803-2808.

25. Fan X, Oertli B, Wuthrich RP (1997) Up-regulation of tubular epithelia interleukin-12 in autoimmune MRL-Fas (Ipr) mice with renal injury. Kidney Int 51: 79-86.
26. Schwarting A, Wada T, Kinoshita K, Tesch G, Kelley VR (1998) IFN-gamma receptor signaling is essential for the initiation, acceleration, and destruction of autoimmune kidney disease in MRL-Fas (Ipr) mice. J Immunol 161: 494-503.

27. Funauchi M, Yu H, Sugiyama M, Ikoma S, Ohno M, et al.(1999) Increased interleukin-4 production by NK T cells in systemic lupus erythematosus. Clin Immunol 92: 197-202.

28. Nozaki Y, Yamagata T, Yoo BS, Sugiyama M, Ikoma S, et al.(2005) The beneficial effects of treatment with all-trans-retinoic acid plus corticosteroid on autoimmune nephritis in NZB/WF mice. Clin Exp Immunol 139: 74-83.

29. Chan TM, Li FK, Tang CS, Wong RW, Fang GX, et al. (2000) Efficacy of mycophenolate mofetil in patients with diffuse proliferative lupus nephritis. Hong Kong-Guangzhou Nephrology Study Group. N Engl J Med 343: 1156-1162.

30. Chan TM, Tse KC, Tang CS, Mok MY, Li FK (2005) Long-term study of mycophenolate mofetil as continuous induction and maintenance treatment fo diffuse proliferative lupus nephritis. J Am Soc Nephrol 16: 1076-1084.

31. Ginzler EM, Dooley MA, Aranow C, Kim MY, Buyon J, et al.(2005) Mycophenolate mofetil or intravenous cyclophosphamide for lupus nephritis. N Engl J Med 353: 2219-2228.

32. Contreras G, Pardo V, Leclercq B, Lenz O, Tozman E, et al. (2004) Sequential therapies for proliferative lupus nephritis. N Engl J Med 350: 971-980.

33. Langevitz P, Klein L, Pras M, Many A (1992) The effect of cyclophosphamide pulses on fertility in patients with lupus nephritis. Am J Reprod Immunol 28 157-158.

34. Allsion AC, Eugui EM (1996) Purine metabolism and immunosuppressive effects of mycophenolate mofetil. Clin Transplant 10: 77-84.

35. Halloran P, Mathew T, Tomlanovich S, Groth C, Hooftman L, et al. (1997) Mycophenolate mofetil in renal allograft recipients: a pooled efficacy analysis of three randomized, double-blind, clinical studies in prevention of rejection. Transplantation 63: 39-47.

36. Dimkovic N, Jovanovic D, Kovacevic Z (2009) Mycophenolate mofetil in highrisk patients with primary glomerulonephritis: results of a 1-year prospective study. Nephron Clin Pract 111: 189-196.

37. Lampropoulos CE, Sangle S, Harrison P, Hughes GR, D'Cruz DP (2004) Topica tacrolimus therapy of resistant cutaneous lesions in lupus erythematosus: a possible alternative. Rheumatology (Oxford) 43: 1383-1385.

38. Anolik JH, Barnard J, Cappione A, Pugh-Bernard AE, Felgar RE, et al. (2004) Rituximab improves peripheral $B$ cell abnormalities in human systemic lupus erythematosus. Arthritis Rheum 50: 3580-3590.

39. Anolik JH, Aringer M (2005) New treatments for SLE: Cell-depleting and anticytokine therapies. Best Pract Res Clin Rheumatol 5: 859-878.

40. Goldberg A, Katzap E (2010) Belimumab for the treatment of systemic lupus erythematosus. Int J Clin Rheum 5: 407-413.

41. Lateer A, Petri M (2010) Biologicals in treatment of SLE. Curr Opin Rheumatol 22: 504-509.

42. Davidson A, Diamond B, Wofsy D, Daikh D (2005) Block and tackle: CTLA4Ig takes on lupus. Lupus 14: 197-203.

43. Schroder JO, Zeuner RA (2009) Biologics as treatment for systemic lupus: great efforts, sobering results, new challenges. Curr Drug Discov Technol 6 : 252-255.

44. Roass SA, Mccaffery PJ, Drager UC, De Luca LM (2000) Retinoids in embryonal development. Physiol Rev 80: 1021-1054.

45. Coombes JL, Siddiqui KR, Arancibia-Cárcamo CV, Hall J, Sun CM, et al. (2007) A functionally specialized population of mucosal CD103+ DCs induces Foxp3+ regulatory $T$ cells via a TGF-beta and retinoic acid-dependent mechanism. Exp Med 204: 1757-1764.

46. Sun CM, Hall JA, Blank RB, Bouladoux N, Oukka M, et al. (2007) Smal intestine lamina propria dendritic cells promote de novo generation of Foxp3 reg cells via retinoic acid. J Exp Med 204: 1775-1785.

47. Valencia X, Yarboro C, Illei G, Lipsky PE (2007) Deficient CD4+CD25high regulatory cell function in patients with active systemic lupus erythematosus. $J$ Immunol 178: 2579-2588.

48. Phoon RK, Kitching AR, Odobasic D, Jones LK, Semple TJ, et al. (2008) T-bet deficiency attenuates renal injury in experimental crescentic glomerulonephritis. J Am Soc Nephrol 19: 477-485. 
Citation: Nozaki Y, Funauchi M, Matsumura I, kinoshita K (2012) New Therapeutic Approach of Retinoids for Lupus Nephritis. J Data Mining in Genom Proteomics 3:112. doi:10.4172/2153-0602.1000112

Page 5 of 5

49. Kitching AR, Holdsworth SR, Tipping PG (1999) IFN-gamma mediates crescent formation and cell-mediated immune injury in murine glomerulonephritis. J Am Soc Nephrol 10: 752-759.

50. Kitching AR, Tipping PG, Holdsworth SR (1999) IL-12 directs severe renal injury, crescent formation and Th1 responses in murine glomerulonephritis. Eur J Immunol 29: 1-10.

51. Mucida D, Park Y, Kim G, Turovskaya O, Scott I, et al. (2007) Reciprocal TH17 and regulatory $\mathrm{T}$ cell differentiation mediated by retinoic acid. Science 317 256-260.

52. Lehrke I, Schaier M, Schade K, Morath C, Waldherr R, et al. (2002) Retinoid receptor-specific agonists alleviate experimental glomerulonephritis. Am J Physiol Renal Physiol 282: 741-751.

53. Schaier M, Lehrke I, Schade K, Morath C, Shimizu F, et al. (2001) Isotretinoin alleviates renal damage in rat chronic glomerulonephritis. Kidney Int 60: 2222 2234.

54. Suzuki A, Ito T, Imai E, Yamato M, Iwatani H, et al. (2003) Retinoids regulate the repairing process of the podocytes in puromycin aminonucleoside-induced nephrotic rats. J Am Soc Nephrol 14: 981-991.

55. Kiss E, Adams J, Gröne HJ, Wagner J (2003) Isotretinoin ameliorates renal damage in experimental acute renal allograft rejection. Transplantation 76 : 480-489.

56. Moreno-Manzano V, Rodriguez-Puyol M, Arribas-Gómez I, Rodríguez-Puyol D, Lucio-Cazaña J (1997) Prevention by tretinoin (all-trans-retinoic acid) of agerelated renal changes. Int J Vitam Nutr Res 67: 427-431.

57. Bennett RT, Mazzaccaro RJ, Chopra N, Melman A, Franco I (1999) Suppression of renal inflammation with vitaminsAand $\mathrm{E}$ in ascending pyelonephritis in rats. J Urol 161: 1681-1684.

58. Oseto S, Moriyama T, Kawada N, Nagatoya K, Takeji M, et al. (2003) Therapeutic effect of all-trans retinoic acid on rats with anti-GBM antibody glomerulonephritis. Kidney Int 64: 1241-1252.
59. Datta PK, Reddy RS, Lianos EA (2001) Effects of all-trans-retinoic acid (atRA) on inducible nitric oxide synthase (iNOS) activity and transforming growth factor $\beta-1$ production in experimental anti-GBM antibody-mediated glomerulonephritis. Inflammation 25: 351-359.

60. Tomita N, Kanamori H, Fujita H, Maruta A, Naitoh A, et al. (2001) Granulomatous tubulointerstitial nephritis induced by all-trans retinoic acid. Anticancer Drugs 12: $677-680$.

61. Seguin-Devaux C, Devaux Y, Latger-Cannard V, Grosjean S, Rochette-Egly C et al. (2002) Enhancement of the inducible NO synthase activation by retinoic acid is mimicked by RARa agonist in vivo. Am J Physiol Endocrinol Metab 283 525-535.

62. Chang MM, Harper R, Hyde DM, Wu R (2000) A novel mechanism of retinoic acid-enhanced interleukin-8 gene expression in airway epithelium. Am J Respir Cell Mol Biol 22: 502-510.

63. Chadwick CC, Shaw LJ, Winneker RC (1998) TNF-a and 9-cis-retinoic acid synergistically induce ICAM-1 expression: Evidence for interaction of retinoid receptors with NF-kappa B. Exp Cell Res 239: 423-429.

64. Nozaki Y, Yamagata T, Yoo BS, Sugiyama M, Ikoma S, et al. (2005) The beneficial effects of treatment with all-trans-retinoic acid plus corticosteroid on autoimmune nephritis in NZB/WF mice. Clin Exp Immunol 139: 74-83.

65. Walsh SJ, Algert C, Gregorio DI, Reisine ST, Rothfield NF (1995) Divergent racial trends in mortality from systemic lupus erythematosus. J Rheumatol 22 1663-1668.

66. Wagner J, Dechow C, Morath C, Lehrke I, Amann K, et al. (2000) Retinoic acid reduces glomerular injury in a rat model of glomerular damage. J Am Soc Nephrol 11: 1479-1487.

67. Morath C, Dechow C, Lehrke I, Haxsen V, Waldherr R, et al. (2001) Effects of retinoids on the TGF-beta system and extracellular matrix in experimental glomerulonephritis. J Am Soc Nephrol 12: 2300-2309. 